\title{
Dew point temperature analyses in ground floor residential room with existing thermal bridge
}

\author{
Martin Ivanov ${ }^{1, *}$ \\ ${ }^{1}$ Technical University - Sofia, FPEPM, Department:" Hydroaerodynamics and Hydraulic Machines", \\ Sofia 1000, Bulgaria
}

\begin{abstract}
The presented study reveals a dew point temperature analyses in ground floor residential room with existing thermal bridge. The dew point temperature is analysed, based on field measurements of indoor air temperature and relative humidity in the residential room, without organized occupants' behaviour. Furthermore, the dew point temperature is cross-analysed with existing thermal bridge propagation in one of the outer walls of the room, via infrared thermal images. The results represent a valuable indicator for moisture accumulation over the thermal bridge zone, as well as an indicator for future mold growth and other humidity related problems. In the building design practice, the "thermal bridge" is defined as a distant zone, where construction elements have higher thermal conductivity, compared with the rest of the building envelope. These thermal bridges mostly affect the energy performance of the buildings, because of the higher heat losses from inside towards outside. But even more important, moisture build-up and considerable humidity related problems in the occupied areas are probable, due to the decreased surface temperature over the affected thermal zones.
\end{abstract}

\section{Introduction}

According to various studies, humidity indoors increases the risk for development of wide range of health problems in the occupants. [1] These may include: respiratory tract infections, asthma, shortness of breath, but also fatigue, weakness and headache. Some studies also suggest that prolonged occupation of humid environment is a risk factor for the development of hypersensitivity and the emergence of allergies. [2,3] However, except for the house dust mites, it is not yet definitely established which components of the indoor air associated with the humidity, are responsible for the existence of these problems. [4]

Nevertheless, it is recognized that excess humid indoor environment is dangerous for the occupants themselves. The moisture in the rooms can exist in the form of water vapor in the air or simply by water, and there are basically four main sources. The first are the external sources, due to the moisture from the ground, outside air and various gaps (leakages), due to rains or prolonged snow. The second are from the internal sources, most often due to the people (occupants), their pets and their activities, like cooking, cleaning, washing, and drying clothes etc. The third are the building sources, which cover the

\footnotetext{
* Corresponding author: $\underline{\mathrm{m} \text { ivanov@tu-sofia.bg }}$
} 
moisture contained in the building materials, like concrete walls and slabs, brick walls, different types of plasters, floor and wall coverings and others. The last are considered all accidental sources, which include the different kinds of leaks from water pipes, floods and others.

An interesting matter is the difference between moisture in the building structure and moisture in the indoor air. Moisture in the building structure can affect the construction materials, leading to microbiological and chemical processes that produce various emissions of odours, allergens and other respiratory irritants. In turn, the relative humidity of indoor air can cause moisture accumulation on cold surfaces and within the structure, which also assists the chemical processes in the development of mold and fungus. This effect my easily happen in thermal bridge areas, where construction elements have higher thermal conductivity, compared with the rest of the building envelope. These construction elements were continuously analysed and improved in the past decades, in terms of thermal properties and influence on the energy efficiency of the buildings. [5] But also, thermal bridges were recognized as important heat transfer paths, and have been presented in the recent construction regulations, in order to avoid their existence. [6]

In reality, thermal bridges still exist in the indoor environment, especially in older residential premises, and it is still important to study the moisture accumulation indicators in such indoor environment. That is why, the presented research is concentrated on the dew point temperature analyses, in a ground floor residential room with confirmed thermal bridge. The dew point temperature is the saturation temperature of the water vapor, which corresponds to the partial pressure of water vapours in the humid air under the specific conditions. Compared with the surface temperature over the thermal bridge area, a direct indicator for moisture accumulation problems, is attained.

Dew point temperature was also previously analysed in extensive long-term study in more than 300 residential rooms, in two of the major cities in Bulgaria [7]. In $32.5 \%$ of the observed rooms in one of the cities and in $28.8 \%$ in the other, the average dew point temperature is higher than $10^{\circ} \mathrm{C}$. These values are significantly high and suggest a high risk of moisture accumulation in the building structure, as well as mold growth over the outer enclosures of the rooms.

\section{Objectives of the study}

The global objective of the presented study is to analyse the dew point temperature, in ground floor residential room with existing thermal bridge, as an indicator for moisture accumulation problems in the indoor environment.

\section{Methods of the study}

The main approach in the presented study consists of field experimental measurements of the microclimate parameters, in real existing ground floor residential room, with confirmed thermal bridge in the floor area. The measured parameters include: room air temperature, wall surface temperature, relative humidity, $\mathrm{CO}_{2}$ concentration, outdoor air temperature and outdoor relative humidity. Some of these measured values are used to calculate and analyse the dew point temperature in the occupied space.

In the environmental engineering practice, various parameters are used to characterize the amount of water vapor in the humid air. The most widely used is the relative humidity in $\%$ - the ratio of the partial pressure of the water vapor dissolved in the air under given conditions, relative to the saturation pressure of the water vapor (the maximum amount of water vapor that can be dissolved in the air) under these conditions. But, in order to assess 
the humidity related problems in the indoor environment, the dew point temperature in ${ }^{\circ} \mathrm{C}$ is also widely used. This parameter represents the saturation temperature of the water vapor, which corresponds to the partial pressure of water vapors in the humid air under the specific conditions.

The saturation pressure of the water vapor as a function of its temperature is calculated from the expression:

$$
p_{s}=100 \exp \left(18.956-\frac{4030.18}{t_{r}+235}\right), P a
$$

where the temperature of the water vapor (and the humid air) $t_{r}$ is in ${ }^{\circ} \mathrm{C}$. This formula is derived in [7], based on ISO 7730 [8]. From this expression, after transformations and taking into account the definitions of relative humidity and dew point temperature [8], the following expression is reached:

$$
t_{d p}=\frac{1}{\frac{1}{235+t_{r}}-\frac{\ln \left(\frac{R H_{r}}{100}\right)}{4030.18}}-235
$$

from which the dew point temperature $\left(t_{d p}\right)$ of the air in a room is calculated as a function of its temperature $\left(t_{r}\right)$ and relative humidity $(\mathrm{RHr})$.

It could be approximated that, the dew point temperature of the air in a given room will be the temperature of the surroundings at which and below which a moisture accumulation will be observed. Typically, the coldest elements in the dwellings are the outer walls and the glass surfaces of windows and outer doors, and most often moisture accumulation is formed on them. But these are also the areas with thermal bridges as well.

The retention of moisture on these surfaces, leads to a decrease in their heat insulation capacity. Moreover, in the presence of suitable nutrient medium and temperature, it may lead to the development of molds of different types. The mold in the premises is recognized as a major respiratory tract irritant and causes a number of respiratory problems, including the development of allergies and asthma.

Instead of the thermal bridges, there are also other situations in which the temperature of the inner surface of the external enclosures becomes lower than the dew point temperature of the air in the room. For example, in homes without central heating, or where the heaters are switched on periodically, the construction elements of the building remain colder and the risk of moisture accumulation on the walls is much higher.

Considering the methods of the presented study, the $\mathrm{CO}_{2}$ concentration measurements have also an important role. The $\mathrm{CO}_{2}$ sources in the selected residence room are only the two occupants, via their metabolic and breathing physiological functions. At first, the expected distinguished build-up and decays in the metabolic $\mathrm{CO}_{2}$ concentration measurements, will show the precise periods, when the room is occupied and not occupied. Second, at the build-up periods, due to the berthing process characteristics, the exhaled air is also with higher temperature and higher relative humidity. As it is mixed with the room air, the room relative humidity and temperature is also changed, which reflect over the dew point temperature in the occupied space. So, it is supposed that, the moisture accumulation over the thermal bridge area will be higher when the metabolic $\mathrm{CO}_{2}$ concentration in the room is higher as well.

The metabolic $\mathrm{CO}_{2}$ concentration is a faster indicator for the aeration rate in the room, compared with the temperature and relative humidity, especially when there is a heating device installed. The longer periods with high $\mathrm{CO}_{2}$ concentration, are indicator for low aeration or infiltration rate in the room. At these periods, when a thermal bridge is established, the risk of moisture accumulation over the thermal bridge inside surface area is significantly high. Thus, at high $\mathrm{CO}_{2}$ concentration levels, there exist an increased risk of 
harmful exposure of the occupants, to different mold growth and spores over the thermal bridges, which may lead to allergies, asthma and other respiratory problems.

The rest of the study methods are also described in [9], which is supplementary paper to the same research. The thermal bridge zone in the selected experimental room is confirmed by preliminary taken thermal images of the outer walls. The short-term measurements were taken in a weekend winter period, with duration of 3 days and 3 nights. In that way, the generic conditions of the thermal bridge existence are much better established, and the selected residential room is occupied by two adults in most of the time, which corresponds to the normal room use. Moreover, the occupant behaviour towards the indoor environment parameters, was not modified by any means.

\section{Experimental set-up and instrumentation}

The experimental room layout in schematically presented on Fig. 1. The room is used for a bedroom and is part of single floor, auxiliary guest house in a property, situated in the western part of Sofia, Bulgaria. The orientation of the widow-wall is South, the floor area is $16 \mathrm{~m}^{2}$, and the room height is $2.80 \mathrm{~m}$. The presented radiator was working continuously during the measurements, maintaining $20{ }^{\circ} \mathrm{C}-21{ }^{\circ} \mathrm{C}$ in the room, without modifying the heating set-point.

The figure also shows a thermal image of the established thermal bridge on the floor area in the corner, between the two external walls. In fact, both walls are well insulated on the outside, but the ground concrete floor is not. Also, in the presented zone, there is a concrete support column, supporting the concrete roof, which is a structural a prerequisite for the thermal bridge existence.

The green points on Fig. 1, denoted by Systems 1, 2, 3 and Outdoor Sensor, represent the positions of the measurement devices. System 1 and System 2 consist of one HOBO data logger (manufactured by ONSET company) in combination with Telaire $7001 \mathrm{CO}_{2}$ sensors, allowing instantaneous measurements of air temperature, relative humidity and $\mathrm{CO}_{2}$ concentration. According to the established measurement standards, the positions of these two systems were selected to be away of the breathing zones of the occupants and away of the walls, on approximately one meter from the ground.

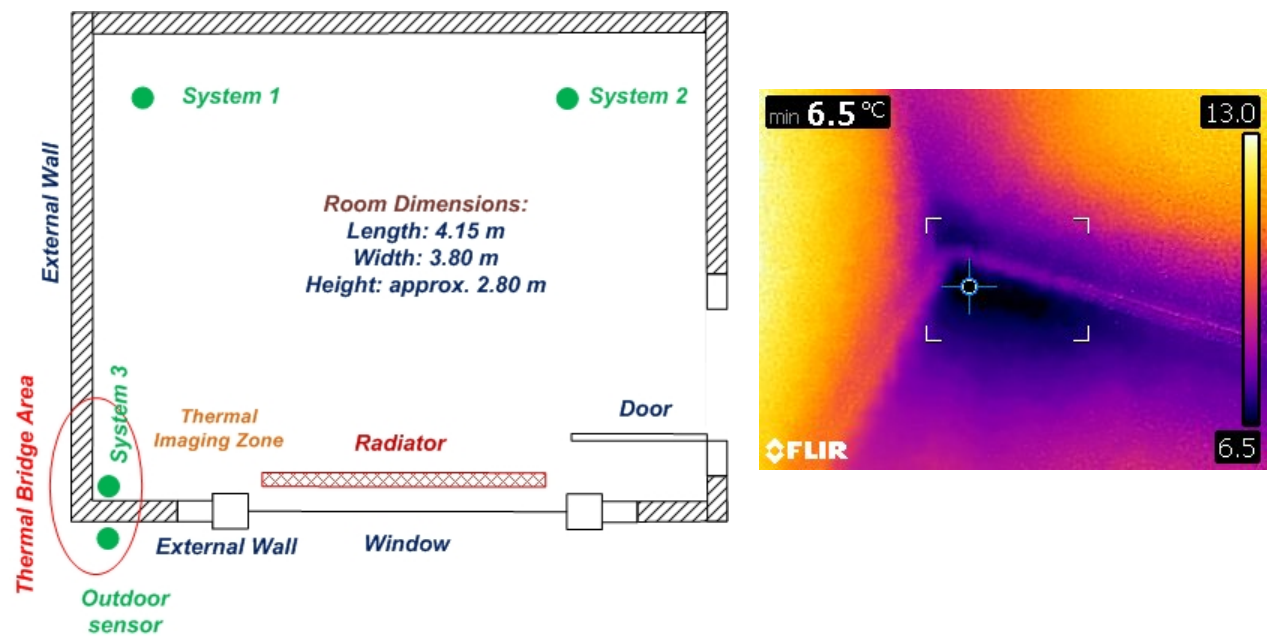

Fig. 1. Experimental room layout and thermal image of the established thermal bridge 
System 3 consist of only one HOBO data logger, for measurement of air temperature and relative humidity, and was installed on the floor of the room, as close as possible to the thermal bridge zone. This is also the zone for the thermal images, taken each evening and each morning, during the experimental period. Over the outside wall surface, on the opposite side of System 3, was placed the Outdoor sensor, providing the outdoor atmospheric conditions in terms of air temperature and air relative humidity. Thermal images in this zone were also taken, during the experimental period.

\section{Results and discussion}

For the purpose of the presented study, only the results for the measured temperatures, relative humidity, $\mathrm{CO}_{2}$ concentration and the calculated dew point temperature will be presented, in terms of figures and tables. The outdoor atmospheric conditions were also measured and presented in [9]. The corresponding parameters, measured in the two room locations, are presented on Fig. 2 and Fig. 3, for both measurement Systems 1 and 2. They are presented in separate graphics, for more clear visualization of the values' distribution. For cross-analyses, the summarized values are shown together in Table 1.

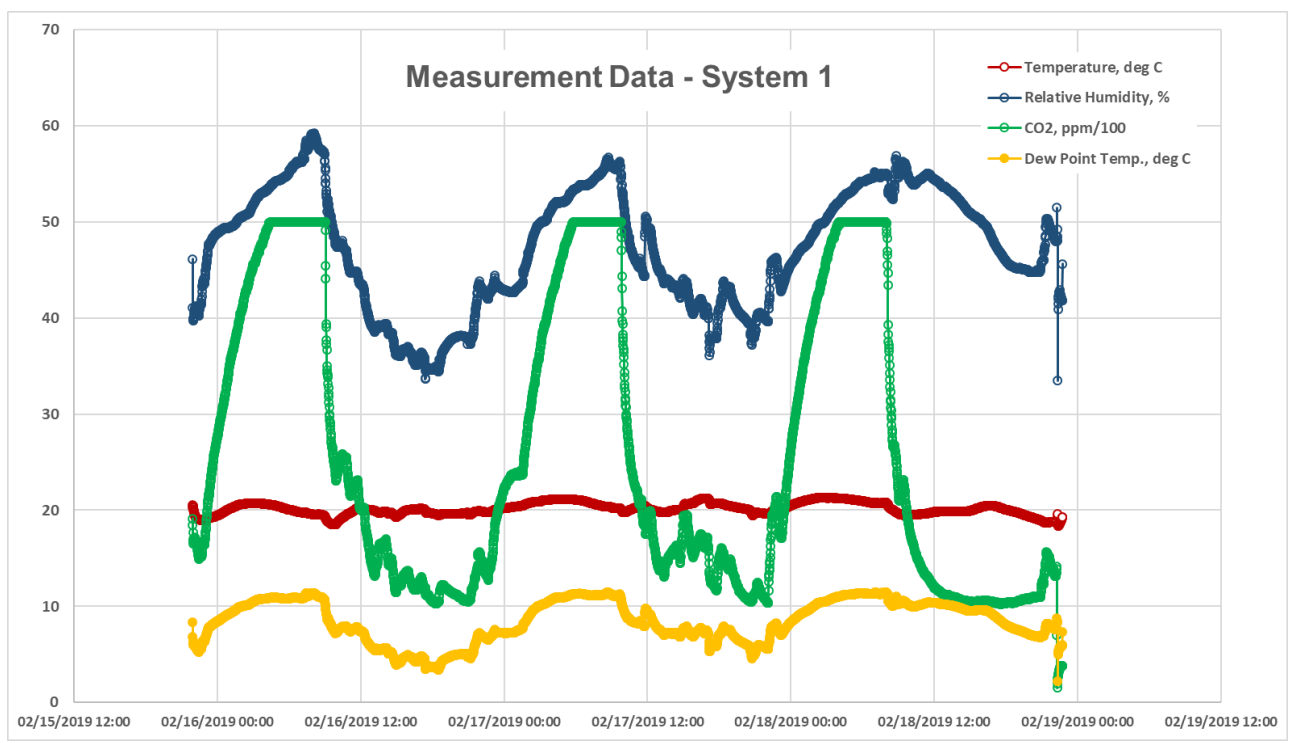

Fig. 2. Measured indoor data for System 1

The processed measurement data for System 1 shows, that the average room air temperature is $20.14{ }^{\circ} \mathrm{C}$, with standard deviation of only $0.62{ }^{\circ} \mathrm{C}$. The minimum and maximum values are $18.39{ }^{\circ} \mathrm{C}$ and $21.32{ }^{\circ} \mathrm{C}$, respectively. The average value of the indoor air relative humidity is $47.29 \%$, with minimum and maximum measured values of $33.53 \%$ and $59.22 \%$, during the entire measurement period.

The measured indoor $\mathrm{CO}_{2}$ concentration varies in large extend for both systems, and the build-up during the occupied night periods is well presented on both Fig. 2 and Fig.3. It should be noted, that the minimum measured values are not correct, since the outdoor environmental $\mathrm{CO}_{2}$ concentration is around $400 \mathrm{ppm}$. There might be an incorrect reading of the sensor, at the end of the experimental period, as shown on the figures. However, the maximum values are correct, and as seen, the real concentration in the room exceeds the maximum measurement capabilities of the sensors $-5000 \mathrm{ppm}$. This result was unexpected and is a clear indicator for low aeration, especially when the room is occupied. The average 
registered concentrations are above $2500 \mathrm{ppm}$, for both system, which is an indicator for low infiltration and exfiltration, and probably for decreased level of indoor air quality.

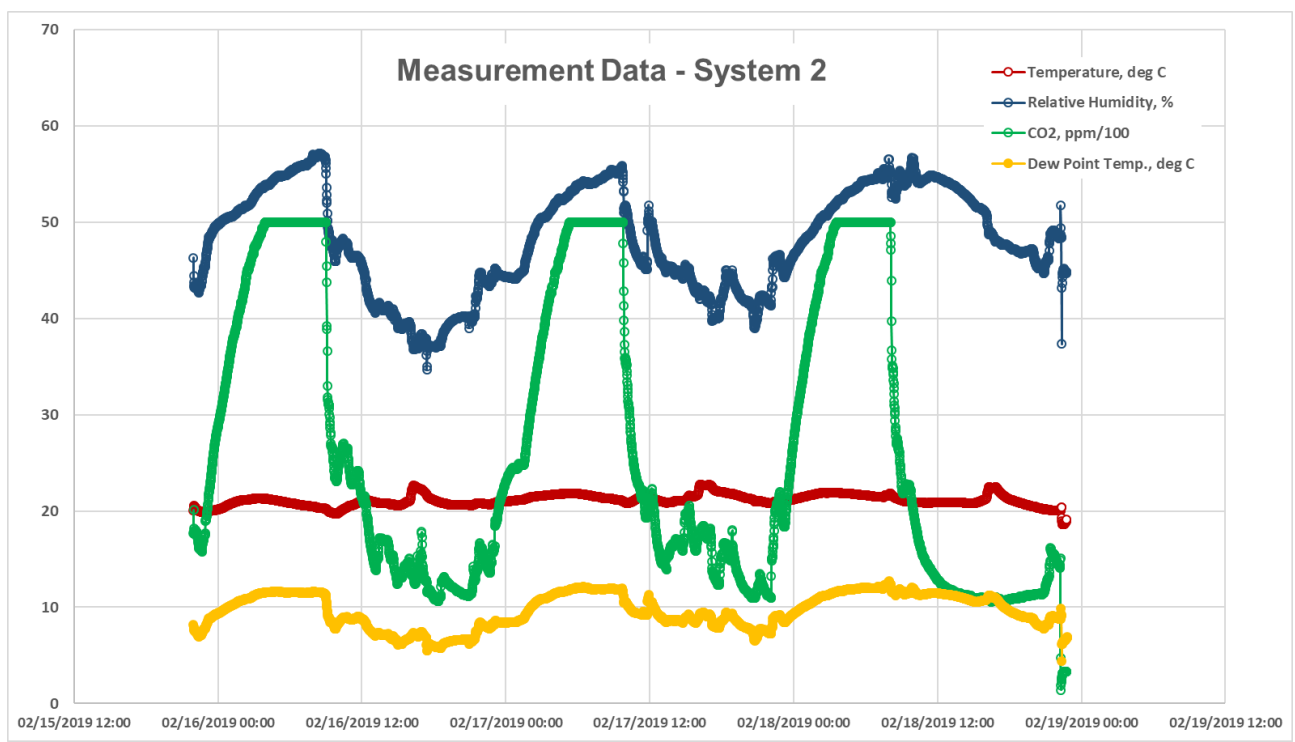

Fig. 3. Measured indoor data for System 2

Table 1. Summarized indoor data for System 1 and System 2

\begin{tabular}{|c|c|c|c|c|}
\hline Indoor condition & $\min$ & $\mathbf{m a x}$ & average & SD \\
\hline System 1 - Temperature, ${ }^{\circ} \mathrm{C}$ & 18.39 & 21.32 & 20.14 & 0.62 \\
\hline System 2 - Temperature, ${ }^{\circ} \mathrm{C}$ & 18.58 & 22.73 & 21.11 & 0.60 \\
\hline System 1 - Relative Humidity, \% & 33.53 & 59.22 & 47.29 & 6.18 \\
\hline System 2 - Relative Humidity, \% & 34.68 & 57.14 & 48.14 & 5.39 \\
\hline System 1 - $\mathrm{CO}_{2}$, ppm & 151.00 & 4998.00 & 2595.55 & 1530.21 \\
\hline System 2 - CO 2 , ppm & 140.00 & 4998.00 & 2661.90 & 1520.61 \\
\hline System 1 - Dew Point Temp., ${ }^{\circ} \mathrm{C}$ & 2.20 & 11.50 & 8.48 & 2.17 \\
\hline System 2 - Dew Point Temp., ${ }^{\circ} \mathrm{C}$ & 4.40 & 12.71 & 9.65 & 1.79 \\
\hline
\end{tabular}

The average dew point temperature, calculated by the measurements of System 1, is $8.48{ }^{\circ} \mathrm{C}$, with standard deviation of $2.17{ }^{\circ} \mathrm{C}$. The minimum and maximum values are 2.20 ${ }^{\circ} \mathrm{C}$ and $11.50{ }^{\circ} \mathrm{C}$, respectively. For the measurements of System 2, the calculated average dew point temperature is $9.65{ }^{\circ} \mathrm{C}$, with standard deviation of $1.79{ }^{\circ} \mathrm{C}$. The minimum and maximum values, for the same system, are $4.40^{\circ} \mathrm{C}$ and $12.71{ }^{\circ} \mathrm{C}$, respectively.

As seen form the figures, the dew point temperature deviates during the experimental period to a higher extend, compared with the room air temperature. The higher values are calculated with the highest relative humidity values, respectively. But also, it could be noted, that when the dew point temperature and relative humidity are higher, the $\mathrm{CO}_{2}$ 
concentration is also higher. This happens especially during the night period, when the room is occupied. And since the room air temperature does not deviate largely, it can be concluded that the occupants themselves are the major factor for excess humidity and high dew point temperature in the room.

This is the point at which the thermal bridge parameters become important factor for future humidity related problems in the presented residence room. That is why, a comparison is made, between the calculated dew point temperatures in Systems 1 and 2, and the measured temperature by System 3. These results are presented on Fig.4. System 3 is situated in very close proximity to the thermal bridge zone, but it does not measure the surface temperature. This system shows the air parameters, near the thermal bridge zone, which are summarized in Table 2. The surface temperature is evaluated by the thermal camera, and the images are analysed in [9]. The minimum measured surface temperature values are also presented in Fig.4. As it can be seen, the measured surface temperature values are significantly lower than the one, measured with the logger, which is expected.

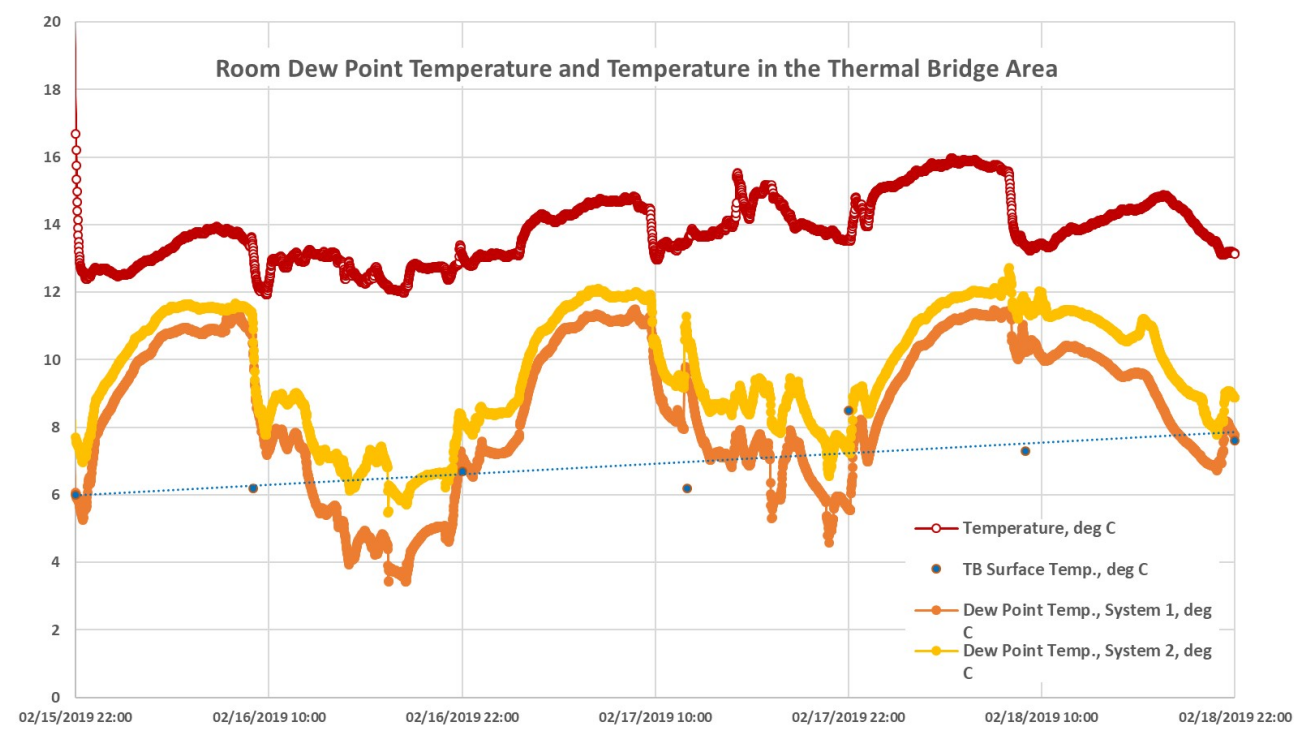

Fig. 4. Calculated room dew point temperatures and measured temperature for System 3

Table 2. Summarized indoor data for System 3

\begin{tabular}{|c|c|c|c|c|}
\hline Indoor data, System 3 & $\mathbf{m i n}$ & $\mathbf{m a x}$ & average & SD \\
\hline Temperature, ${ }^{\circ} \mathrm{C}$ & 11.93 & 20.29 & 13.89 & 1.06 \\
\hline Relative Humidity, \% & 39.67 & 83.77 & 67.56 & 8.13 \\
\hline Dew Point Temp., ${ }^{\circ} \mathrm{C}$ & 1.73 & 11.46 & 7.90 & 2.18 \\
\hline
\end{tabular}

As seen on Fig. 4 and in Table 2, the average measured temperature in the thermal bridge zone is $13.89{ }^{\circ} \mathrm{C}$, with standard deviation of $1.06{ }^{\circ} \mathrm{C}$ for the entire experimental period. The minimum and maximum values are respectively $11.93{ }^{\circ} \mathrm{C}$ and $20.29{ }^{\circ} \mathrm{C}$. For the relative humidity in the same zone, the measured average value is $67.56 \%$. The minimum and maximum values are $39.67 \%$ and $83.77 \%$, respectively. The values of the minimum 
surface temperature, measured by the thermal camera, are presented in Table 3, with the corresponding imaging time.

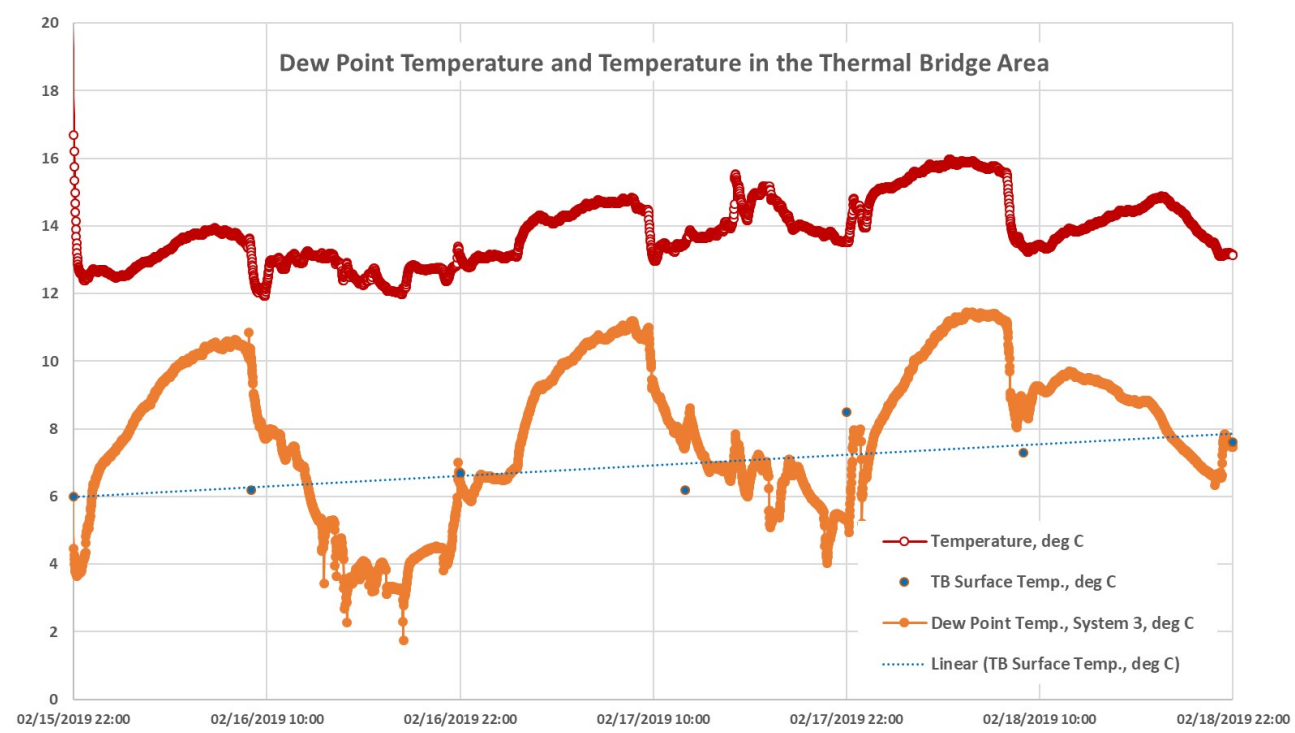

Fig. 5. Measured temperature and calculated dew point temperature with the values for System 3

Table 3. Minimum values of the surface temperatures in the thermal bridge zone

\begin{tabular}{|c|c|c|c|}
\hline 2/15/19 22:00h & $\mathbf{2 / 1 6 / 1 9 ~ 9 : 0 0 h}$ & $\mathbf{2 / 1 6 / 1 9 ~ 2 2 : 0 0 h}$ & $\mathbf{2 / 1 7 / 1 9 ~ 1 2 : 0 0 h}$ \\
\hline $6.0^{\circ} \mathrm{C}$ & $6.2^{\circ} \mathrm{C}$ & $6.7^{\circ} \mathrm{C}$ & $6.2^{\circ} \mathrm{C}$ \\
\hline 2/17/19 22:00h & $2 / 18 / 199: 00 h$ & \multicolumn{2}{|c|}{$\mathbf{2 / 1 8} / \mathbf{1 9} 22: 00 h$} \\
\hline $8.5^{\circ} \mathrm{C}$ & $7.3^{\circ} \mathrm{C}$ & \multicolumn{2}{|c|}{$7.6^{\circ} \mathrm{C}$} \\
\hline
\end{tabular}

Compared with the rest of the residence room, the presented results for the thermal bridge zone clearly show significantly lower values of the air temperature and significantly higher values of the relative humidity. This is a prerequisite for constant heat losses through the thermal bridge zone. The higher values of the relative humidity in this zone indicates the possibility for moisture related problems on the surface of the external wall. But, this effect is not so clear from the comparison between the dew point temperature distribution in the room and the values, measured near the thermal bridge zone. The two graphs go closer, but do not cross each other.

However, comparing the surface temperatures, measured by the thermal camera, it is clear that large time intervals exist, in which the dew point temperature is higher than the surface temperature in the thermal bridge zone. For the presented weekend period, there are distinguished three such periods. This result is well shown on Fig. 5, where the dew point temperature distribution is calculated with the values measured in the thermal bridge zone, by System 3. Obviously, in these peak periods, moisture accumulation over the thermal bridge surface is expected. In this case, the thermal camera may account better for the heat loss trough the solid surface of the wall and seem to be better way for establishing the cold spots of the thermal bridge areas. 
In general, the summarized measurement data for the two systems shows relatively high degree of homogeneity in the indoor air temperature and relative humidity distribution in the experimental room. In most of the time, the measured values are in the comfortable range for the indoor environment requirements for the winter season. The huge exception is the measured $\mathrm{CO}_{2}$ concentration values, and additional measures for aeration should be taken. The small differences in the measured values between the two systems show, that the mixing of the room air is not perfect. That is why, a use of a small fan for mixing the room air is recommended is such experimental studies. Nevertheless, the deviations between the results in the two measurement points are considerably small. This means that, the thermal bridge parameters are more accurately defined, and the measured generic conditions are more precisely studied.

It is considered, that all presented results would assist future numerical modelling of the related phenomena. For the accurate modelling of the conjugated heat transfer in similar set-ups, the measured and presented above air temperature around the solid cold surfaces, is an important generic parameter for the thermal bridge simulation. Collecting such experimentally measured values is considered as innovative approach in the field. The development of accurate numerical model for simulation of the thermal bridge distribution, will be the next step in the presented research study.

\section{Conclusions}

Dew point temperature analyses is performed, in ground floor residential room with existing thermal bridge. The experimental data is collected by conducting field measurements of indoor air and thermal bridge parameters, in real existing ground floor premises. The analyses of the results demonstrated the generic conditions for the thermal bridge existence, without considering the building structure.

The summarized measurement data for the two systems shows relatively high degree of homogeneity in the indoor air temperature and relative humidity distribution in the experimental room. In most of the time, the measured values are in the comfortable range for the indoor environment requirements for the winter season.

However, the measured $\mathrm{CO}_{2}$ concentration values are significantly high, considering that there were only two occupants in the room. This is an indicator for low aeration and low infiltration and exfiltration, and probably for decreased level of indoor air quality.

The general results show, that during the experimental period, the dew point temperature deviates to a higher extend, compared with the room air temperature. The higher values are calculated with the highest relative humidity values, respectively.

The high levels of the dew point temperature and the relative humidity correspond with the high level of the $\mathrm{CO}_{2}$ concentration. Thus, the occupants themselves are the major factor for excess humidity and high dew point temperature in the room, since the room air temperature does not deviate largely.

The results for the thermal bridge zone clearly show significantly lower values of the air temperature and significantly higher values of the relative humidity, compared with the rest of the rom. This is a prerequisite for constant heat losses through the thermal bridge zone. The higher values of the relative humidity in this zone indicates the possibility for moisture related problems on the surface of the external wall.

The comparison with the measured surface temperatures, performed by the thermal camera, clearly show large time intervals, in which the dew point temperature is higher than the surface temperature in the thermal bridge zone. In these peak periods, moisture accumulation over the thermal bridge surface is expected. 
The global results show, that in such experimental set-ups, the thermal imaging camera may account better for the heat loss trough the solid surface of the wall and seem to be better way for establishing the cold spots of the thermal bridge areas.

It is believed, that all presented results would assist future numerical modelling of the related thermal bridge phenomena, which will be the next step in the presented research study. For the accurate modelling of the conjugated heat transfer in similar set-ups, the measured and presented above air temperature around the solid cold surfaces, is an important generic parameter for the thermal bridge simulation.

\section{Acknowledgements}

The presented study is supported by the National Science Fund at the Ministry of Education and Science of Bulgaria, under the activities of: "Competition for financial support for projects of junior basic researchers and postdocs - 2018", with Contract № КП-06-M27/4, entitled: "Numerical assessment of effective measures for prevention of moisture accumulation on external walls with thermal bridge, in residential rooms without organized ventilation".

\section{References}

[1] CG. Bornehag, J. Sundell, L. Hagerhed, S. Jason, and the DBH study group. „Dampness in buildings and health. Dampness at home as a risk factor for symptoms among 10851 Swedish children (DBH-step I)", Proc. to Indoor Air Conference 2002, 431436, (2002)

[2] Institute of Medicine, "Clearing the air. Asthma and Indoor Air Exposures", The National Academy Press, Washington, (2000)

[3] M. Ivanov, D. Markov, P. Stankov, "On the research of the parameters of the indoor environment in Bulgarian homes, based on the experimental project ALLHOME”, J. „Heat Tech. for Everyday Life", ISSN 1310-9405, Issue 4, pp. 13-17, (2010)

[4] M. Ivanov, D. Markov, "Analyses and assessment of the indoor air quality in residence rooms in Bulgaria and comparison with the Bulgarian norms and foreign standards, based on the ALLHOME Project”, Proc. to: „Int. Sc. Conf. UNITECH'10”, Vol. III, pp. 558-564, ISSN 1313-230X, (2010)

[5] T. Theodosiou, K. Tsikaloudaki, S. Tsoka, P. Chastas, "Thermal bridging problems on advanced cladding systems and smart building facades”, J. Clean. Prod., 214, 62-69 Elsevier (2019)

[6] A. Papadopoulos, "Forty years of regulations on the thermal performance of the building envelope in Europe: achievements, perspectives and challenges”, Energy Build. 127. https://doi.org/10.1016/j.enbuild.2016.06.051, (2016)

[7] M. Ivanov, D. Markov, "Analyses and assessment of the dew point temperature in Bulgarian homes, based on results of the ALLHOME project", Proc. to "Int. Sc. Conf. in Ruse'10", Vol.49, Series 1.2, pp. 14-18, (2010)

[8] ISO 7730, "Ergonomics of the thermal environment - Analytical determination and interpretation of thermal comfort using calculation of the PMV and PPD indices and local thermal comfort criteria", International Organization for Standardization, (2006)

[9] M. Ivanov, "Instantaneous field measurements of thermal bridge parameters in ground floor residential room", Submitted for publishing in: Proc. of "8th Int. Conf. on Thermal Equipment, Renewable Energy and Rural Development - TE-RE-RD’19”, (2019) 